\title{
A Case of Waldenstrom Macroglobulinemia/ Lymphoplasmacytic Lymphoma Associated with Nephrotic Syndrome during Hemodialysis, Treated Successfully with Tirabrutinib
}

\author{
Yasunobu Sekiguchi ${ }^{1}$, You Nishimura ${ }^{2}$, Hiroaki Kanda ${ }^{2}$, Machiko Kawamura ${ }^{3}$, \\ Kazuhiko Kobayashi ${ }^{3}$ and Hirofumi Kobayashi ${ }^{1}$
}

\begin{abstract}
:
A 74-year-old woman was diagnosed with Waldenstrom macroglobulinemia/lymphoplasmacytic lymphoma (WM/LPL) in X-18. Fludarabine plus rituximab (FR) was started, and she showed remission. In July X-7, the serum creatinine $(\mathrm{Cr})$ level increased to $1.67 \mathrm{mg} / \mathrm{dL}$, and bendamustine plus rituximab (BR) was started. By November X-7, the Cr level had increased to $8.41 \mathrm{mg} / \mathrm{dL}$, so she was started on hemodialysis (HD). In September X-1, she developed nephrotic syndrome. She was started on tirabrutinib at $480 \mathrm{mg}$. In July X, her nephrotic syndrome had improved, and a complete response (CR) was achieved. This is the first case of the administration of tirabrutinib in a patient undergoing HD.
\end{abstract}

Key words: Waldenstrom macroglobulinemia/lymphoplasmacytic lymphoma (WM/LPL), tirabrutinib, chronic renal failure, nephrotic syndrome, hemodialysis

(Intern Med Advance Publication)

(DOI: 10.2169/internalmedicine.8760-21)

\section{Introduction}

Tirabrutinib is a second-generation inhibitor of Bruton tyrosine kinase (BTK) and has been found to have fewer offtarget effects than the first-generation inhibitors (1-4). Clinical studies have also reported fewer adverse events and a higher response rate to tirabrutinib (3-6). However, use of this drug in clinical practice has not yet been reported.

Japan is the only country in the world in which tirabrutinib has been launched in the market, allowing the drug to be used in clinical practice. At present, a number of clinical studies are ongoing overseas (6), and tirabrutinib is expected to be launched in the market outside of Japan in the near future. Therefore, it is important to report experience of using tirabrutinib in clinical practice in Japan.

We herein report a patient with Waldenstrom macroglobulinemia/lymphoplasmacytic lymphoma (WM/LPL)-related renal dysfunction and nephrotic syndrome who was success- fully treated with tirabrutinib in combination with hemodialysis (HD).

\section{Case Report}

A 74-year-old woman with no significant medical or family history developed left mandibular swelling and low back pain in X-19. Her subsequent clinical course is shown in Fig. 1 (A, B).

In November X-18, she visited our hospital (Fig. 1A). Table shows the laboratory findings at her first visit. An examination of a peripheral blood smear revealed the presence of $3 \%$ atypical lymphocytes. The plasma soluble interleukin2 (IL-2) receptor level was 3,725 international units (IU)/ $\mu \mathrm{L}$, and the plasma IgM level was $2,565 \mathrm{mg} / \mathrm{dL}$. Serum immunoelectrophoresis revealed a positive result for IgM- $\kappa$. She was found to have a gingival tumor in the left mandible, and a biopsy was performed. A histopathological examination of sections stained with hematoxylin and eosin (HE) revealed

${ }^{1}$ Department of Hematology, Saitama Cancer Center, Japan, ${ }^{2}$ Department of Pathology, Saitama Cancer Center, Japan and ${ }^{3}$ Department of Clinical Laboratory Medicine, Saitama Cancer Center, Japan

Received: October 1, 2021; Accepted: December 12, 2021; Advance Publication by J-STAGE: February 1, 2022

Correspondence to Dr. Yasunobu Sekiguchi, yasu_sek@saitama-pho.jp 

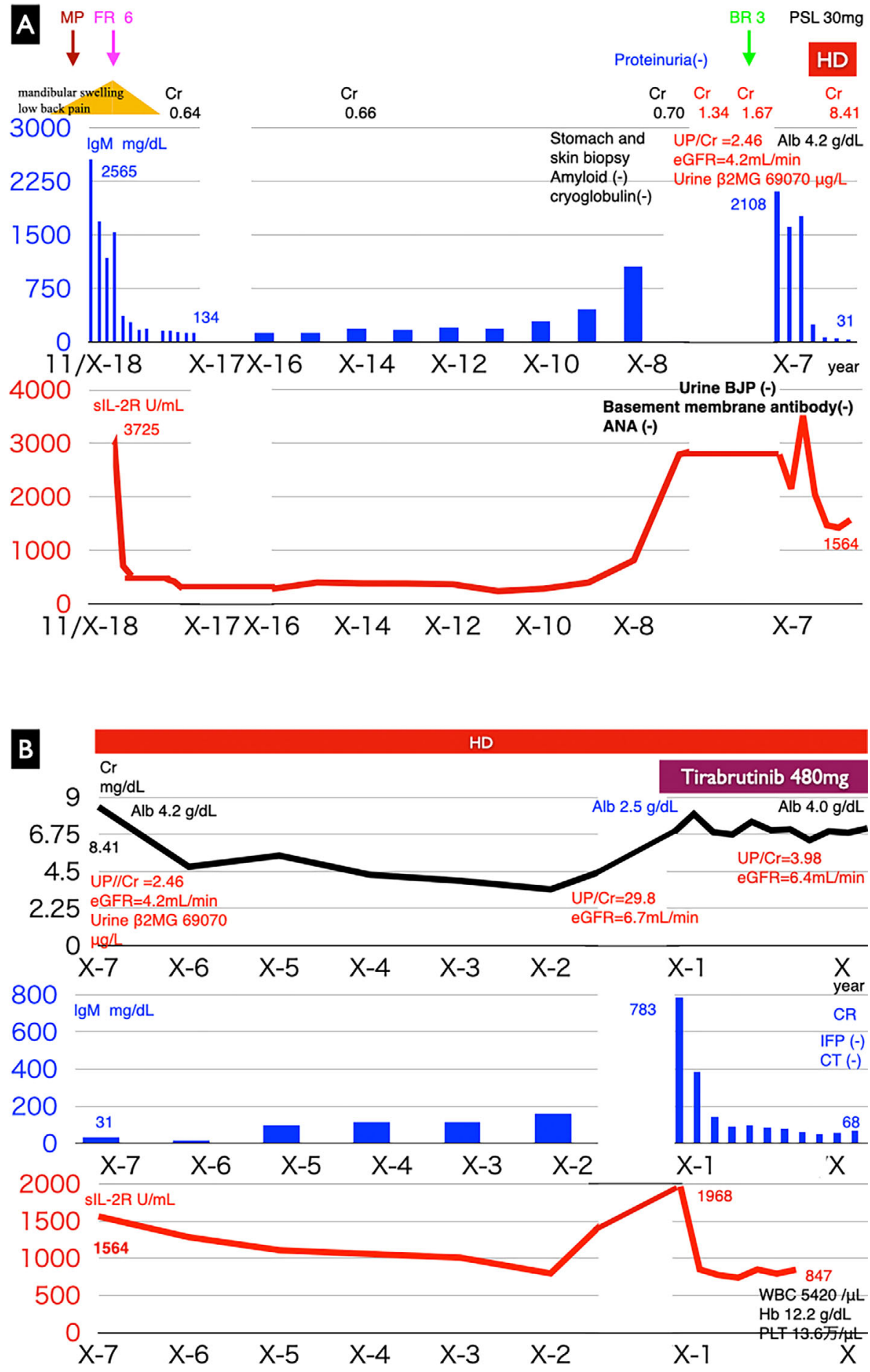

Figure 1. Clinical course. A: From the onset to the initiation of HD. B: From the initiation of HD to the present. MP: Melphalan, Prednisolone, FR: Fludarabine, Rituximab, sIL-2R: soluble IL-2 receptor, BUN: blood urea nitrogen, Cr: Creatinine, BR: Bendamustine, Rituximab, UP: Urine protein, eGFR: estimated glemerular filtration rate, min: minute, MG: Microglobulin, BJP: Bence-Jones protein, PSL: Prednisolone, HD: Hemodialysis, Alb: albumin, CR: Complete remission, IFP: Immunofixation method, WBC: White blood cells, Hb: Hemoglobin, PLT: platelet

proliferation of atypical plasmacytoid lymphocytes (Fig. 2A). On immunohistochemistry, the cells showed positive staining for CD 20, CD138, immunoglobulin M (IgM), and $\kappa$ chain and negative staining for $\lambda$ chain (Fig. 2B-F). Based on the above findings, she was diagnosed with LPL.

Computed tomography (CT) revealed multiple lymphade- nopathies and hepatosplenomegaly (data not shown). Magnetic resonance imaging (MRI) revealed multiple bone lesions (data not shown). A bone marrow examination showed an increase in medium-sized lymphocytes (26.4\%) with nuclear atypia (Fig. 2G, H). Among cell surface markers, the cells were positive for CD20 (data not shown). Based on 
Table. Laboratory Findings at the First Visit to Our Hospital.

\begin{tabular}{|c|c|c|c|c|c|}
\hline \multicolumn{2}{|l|}{ CBC } & \multicolumn{2}{|c|}{ Biochemistry } & \multicolumn{2}{|c|}{ Immuno-Serological findings } \\
\hline WBC & $9,330 / \mu \mathrm{L}$ & T.P & $8.8 \mathrm{~g} / \mathrm{dL}$ & HTVL-I & negative \\
\hline Seg & $56.0 \%$ & Alb & $4.0 \mathrm{~g} / \mathrm{dL}$ & HIV Ab & negative \\
\hline Eo & $1.0 \%$ & BUN & $11 \mathrm{mg} / \mathrm{dL}$ & HBsAg & negative \\
\hline $\mathbf{B a}$ & $1.0 \%$ & $\mathrm{Cr}$ & $0.57 \mathrm{mg} / \mathrm{dlL}$ & HBsAb & negative \\
\hline Mono & $5.0 \%$ & T-Bil & $1.1 \mathrm{mg} / \mathrm{dL}$ & HBcAb & negative \\
\hline Lympho & $34.0 \%$ & AST & $13 \mathrm{IU} / \mathrm{L}$ & HCVAb & negative \\
\hline Aty Lym & $3.0 \%$ & ALT & 4 IU/L & IgG & $1027 \mathrm{mg} / \mathrm{dL}$ \\
\hline RBC & $313 \times 10^{4} / \mu \mathrm{L}$ & LDH & 119 IU/L & IgA & $49 \mathrm{mg} / \mathrm{dL}$ \\
\hline Hb & $10.2 \mathrm{~g} / \mathrm{dL}$ & ALP & 516 IU/L & IgM & $2565 \mathrm{mg} / \mathrm{dL}$ \\
\hline Het & $31.9 \%$ & AMY & $40 \mathrm{IU} / \mathrm{L}$ & ANA & $<40$ times \\
\hline MCV & $102 \mathrm{fL}$ & $\gamma-$ GTH & $13 \mathrm{IU} / \mathrm{L}$ & Serum I & IgM-к \\
\hline МCH & $32.5 \mathrm{pg}$ & $\begin{array}{l}\text { T-CHO } \\
\text { BS } \\
\text { CRP }\end{array}$ & $\begin{array}{l}200 \mathrm{mg} / \mathrm{dL} \\
89 \mathrm{mg} / \mathrm{dL} \\
2.9 \mathrm{mg} / \mathrm{dL}\end{array}$ & & \\
\hline
\end{tabular}

\begin{abstract}
Abbreviation;WBC, white blood
cells;Seg,segmented;Eo,eosinophil;Ba,basophil;Mono,monocyte;Lympho,lymphocyte;RBC,r ed blood cell;Hb,hemoglobin;Hct,hematocrit; $\mathrm{MCV}$,mean corpuscular volume; $\mathrm{MCH}$,mean corpuscular hemoglobin;T.P,total protein;Alb,albumin;BUN,blood urea nitrogen;Cr,creatine;T-BIL,total-bilirubin;AST,aminotransferase;ALT,alanine aminotransferase;

LDH,lactate dehydrogenase;ALP,alkaline phosphatase;AMY,amylase: $\gamma$-GTP, $\gamma$-guanosine triphosphate;T-CHO,total cholesterol;BS,blood sugar;CRP,C-reactive protein; sIL-2R,soluble interleukin-2 receptor;HTLV-1 Ab,human T-cell leukemia virus type 1 antibody;HIV Ab,human immunodeficiency virus antibody:HBsAg, hepatitis B virus antigen;HBsAb, hepatitis $B$ virus antibody; $\mathrm{HBcAb}$,hepatitis $B$ virus core antibody; $\mathrm{HCV}$ Ab,hepatitis $\mathrm{C}$ virus antibody ; IgG,immunoglobulin G;IgA,immunoglobulin A;IgM,immunoglobulin M;ANA, antinuclear antibody;IEP,Immunoelectrophoresis
\end{abstract}

these findings, she was diagnosed with WM/LPL (7). The test for an MYD88 mutation in a specimen of bone marrow aspirate was negative.

She was assessed as having a low risk according to the International Prognostic Scoring System for Waldenstrom Macroglobulinemia (ISSWM) (8). She complained of severe low back pain and was started on melphalan plus prednisolone (MP) therapy. However, the effect was only transient, and the treatment was switched to fludarabine plus rituximab (FR) therapy. The low back pain resolved, and the plasma $\mathrm{M}$ protein level decreased in response to this treatment. She was administered six courses of chemotherapy and subsequently followed up.

The plasma $\mathrm{M}$ protein level began to increase gradually from $\mathrm{X}-10$, and evidence of renal function impairment was detected in April X-7 (creatinine [Cr], $1.34 \mathrm{mg} / \mathrm{dL}$ ). She was diagnosed with renal dysfunction caused by WM/LPL (WM/ LPL-related renal dysfunction).

In July X-7, the $\mathrm{Cr}$ increased to $1.67 \mathrm{mg} / \mathrm{dL}$, and she was started on bendamustine plus rituximab (BR) therapy. Although the plasma $\mathrm{M}$ protein level decreased, the renal impairment worsened rapidly. She was started on $30 \mathrm{mg} /$ day of prednisolone, but the renal parameters failed to improve. By November X-7, the Cr level had increased to $8.41 \mathrm{mg} / \mathrm{dL}$, and she was started on maintenance HD (3 days a week: Mondays, Wednesdays, and Fridays). The urinary protein/Cr ratio was 2.46. The serum albumin level (Alb) was $4.2 \mathrm{~g} / \mathrm{dL}$. She did not consent to undergo a renal biopsy. The qualitative test for cryoglobulin was negative. Stomach and skin biopsies revealed no evidence of amyloid depositions. The uri- nary test for Bence-Jones protein was negative. Basement membrane antibody was negative.

The plasma $\mathrm{M}$ protein level increased gradually. In September X-1, the serum Alb decreased to $2.5 \mathrm{~g} / \mathrm{dL}$ and the urinary protein/Cr ratio increased to 29.8 (Fig. 1B). She was diagnosed with nephrotic syndrome (9). CT revealed multiple superficial lymphadenopathies but no hepatosplenomegaly or bone lesions (data not shown).

She was started on tirabrutinib at $480 \mathrm{mg}$ once daily. On the scheduled HD days, tirabrutinib was administered after the HD session, as the drug removal rate of tirabrutinib during $\mathrm{HD}$ is still unknown. The plasma $\mathrm{M}$ protein level decreased. In July X, the Alb level increased to $4.0 \mathrm{~g} / \mathrm{dL}$ and the urinary protein/Cr ratio improved to 3.98. Immunofixation electrophoresis (IFP) yielded negative findings, and CT no longer showed lymphadenopathy or hepatosplenomegaly. A bone marrow examination also revealed no abnormalities, and she was determined to have shown a complete response (CR) (10). At present, in October X, she continues to receive tirabrutinib and has developed no adverse events (AEs).

\section{Discussion}

According to reports, MYD88 mutations are seen in 70\%$90 \%$ of patients with WM/LPL, but some patients with WM/ LPL are negative for MYD88 mutations (11). Thus, the absence of MYD88 mutations does not necessarily exclude WM/LPL. Furthermore, $37.1 \%$ of Japanese patients with $\mathrm{WM} / \mathrm{LPL}$ are reported to have bone lesions (11), so the 

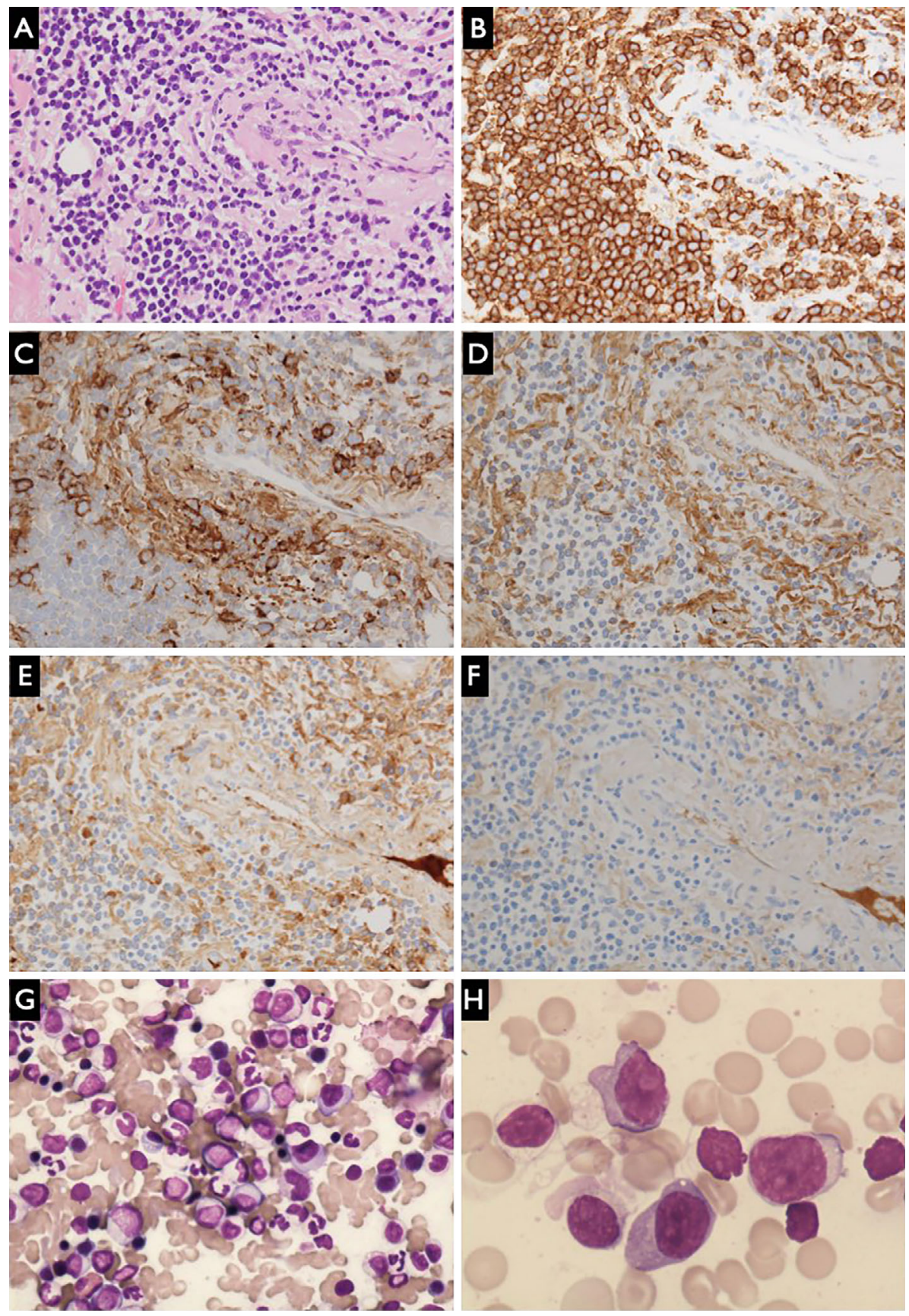

Figure 2. A-F: Biopsy of the gingival tumor, G, H: Bone marrow. A: Hematoxylin and Eosin staining $\times 40$; Proliferation of atypical plasmacytoid lymphocytes is observed. B: CD20 $\times 40$; positive. C: CD138 $\times 40$; positive. D: IgM $\times 40$; positive. $\mathrm{E}$ : $\kappa \times 40$; positive. $\mathrm{F}$ : $\lambda \times 40$; negative. G: Smear $\times 400$; Medium-sized lymphocytes with nuclear atypia increased. H: Smear×1,000; Medium-sized lymphocytes with nuclear atypia increased.

presence of bone lesions cannot serve as a basis for excluding WM/LPL. A biopsy of the gingival tumor and examination of the bone marrow aspirate revealed atypical plasmacytoid lymphocytes that were CD20-positive. Based on the above findings, multiple myeloma was excluded, and the patient was diagnosed with WM/LPL.

Tirabrutinib has yet to be launched in markets outside of Japan, and major overseas guidelines (National Comprehensive Cancer Network [NCCN] and European Society for Medical Oncology [ESMO] guidelines) do not cover tirabru- tinib 12,13. The Japanese Society of Hematology guidelines also do not cover it, as they have not been revised since the date of approval of this new drug (August 21, 2020) (14). The optimal clinical indications and timing for treatment with tirabrutinib in clinical practice are still unknown. In addition, whether or not tirabrutinib is effective in patients with WM-related renal failure or nephrotic syndrome is also still unknown, as is the drug's effect in patients on HD. It would be desirable to accumulate experience and establish evidence concerning the safety and efficacy of tirabrutinib in 
clinical practice in Japan.

Thile the first-generation BTK inhibitor ibrutinib is known to show scarce renal excretion (15), its pharmacokinetics and pharmacodynamics in HD patients remain unknown (15). The drug removal rate of ibrutinib through HD also unknown. Only two cases of ibrutinib use in HD patients have been reported $(15,16)$. In one case, a patient with chronic lymphocytic leukemia received ibrutinib for two weeks, and HD was able to be suspended (16). In the other case, a patient with mantle cell lymphoma continued to receive ibrutinib for 15 months (15). There were no serious AEs in either case, and ibrutinib was effective, suggesting that ibrutinib is also safe and effective in patients undergoing HD, although further evidence is still needed $(15,16)$.

In cases of WM associated with renal failure, it is necessary to differentiate between WM-related renal failure and other causes of renal failure (e.g. diabetes mellitus, hypertension, malignant tumors, and drug-induced) (17). The present patient was considered to have WM-related renal dysfunction, because the renal function worsened in parallel with the progression of WM/LPL (increase of the plasma levels of $\mathrm{M}$ protein and soluble IL-2 receptor) (Fig. 1B), and there was no evidence of other causes of renal failure mentioned above.

WM-related renal failure is relatively rare, with a cumulative incidence of $5.1 \%$ at 15 years, and carries a poor prognosis (17). There are a number of mechanisms underlying the development of the failure, including amyloidosis, $\operatorname{IgM}$ deposition/cryoglobulinemia, LPL infiltration, light chain deposition, and light chain cast nephropathy $(17,18)$. A renal biopsy is required to determine the precise cause $(17,18)$.

WM-related renal failure sometimes progresses to a stage requiring renal replacement therapy (RRT) $(17,19)$. After progression to the stage of nephrotic syndrome, conservative treatment has been reported to be effective in only half of patients (17). WM-related renal failure has a poor prognosis (17) and needs appropriate treatment; however, the optimal treatment is still unknown (20). In addition, it has been reported that a decrease in the plasma $\mathrm{M}$ protein level (hematologic response) is not always directly related to improvement of the renal function $(19,21)$. Caution should be exercised in its treatment. In fact, in the present case, BR therapy decreased the plasma $M$ protein level but did not improve the renal function, necessitating the initiation of maintenance HD (Fig. 1A). When these patients begin to show evidence of renal impairment, early and appropriate treatment is necessary 17.

In the present case, stomach and skin biopsies revealed no evidence of amyloid deposition, and the qualitative test for serum cryoglobulin was negative (Fig. 1A). We believe that amyloidosis and IgM/cryoglobulin deposition were unlikely. In three previous cases of WM/LPL, treatment elicited a hematologic response, but HD could not be discontinued $(19,21)$. A histopathological examination of the kidney in these three cases revealed rapidly progressive glomeru- lonephritis (RPGN) in one case, cast nephropathy in one case, and light-chain deposition disease (LCDD) in one case. It is suspected that these lesions were irreversible. The renal lesion in the present case was also irreversible, suggesting that the findings probably corresponded to one of the above diseases.

There have been no reports of tirabrutinib administration in patients with severe renal failure (estimated glomerular filtration rate $[\mathrm{eGFR}]$ of $\leq(30)$ or those on maintenance HD (these patients have been excluded from clinical studies so far) $(4,5,22-24)$. Therefore, the efficacy and safety of the drug in these patients are unknown. In addition, the removal rate of this drug by HD is also unknown (21). Since unchanged tirabrutinib was not detected in the urine (25), it is presumed that the drug is metabolized in the liver. Theoretically, tirabrutinib can be administered to patients with renal failure. However, whether or not its removal by HD might also reduce its efficacy is unknown.

In the present case, the nephrotic syndrome (WM/LPLrelated renal dysfunction) improved (urinary protein/Cr ratio decreased from 29.8 to 3.98 and serum Alb level increased from $2.5 \mathrm{~g} / \mathrm{dL}$ to $4.0 \mathrm{~g} / \mathrm{dL}$ ), and CR of WM/LPL was achieved (Fig. 1E). No AEs were observed. The results suggest that tirabrutinib is effective and safe in patients with WM/LPL-related renal failure on HD.

Several limitations associated with the present study warrant mention. First, we did not perform a renal biopsy and thus could not examine the renal lesion in detail. Second, treatment with tirabrutinib was started six years after the initiation of HD, and it is considered difficult to withdraw a patient from HD even after improvement of nephrotic syndrome. Third, the follow-up period was short at approximately one year.

In conclusion, we encountered a patient who was treated on tirabrutinib while undergoing maintenance HD. The nephrotic syndrome was successfully controlled by tirabrutinib, and CR of WM/LPL was achieved. Although the results suggest that tirabrutinib may be useful in WM/LPL patients undergoing maintenance $\mathrm{HD}$, the further accumulation of cases and longer-term follow-up are necessary.

\section{The authors state that they have no Conflict of Interest (COI).}

\section{References}

1. Wu J, Liu C, Tsui ST, Liu D. Second-generation inhibitors of Bruton tyrosine kinase. J Hematol Oncol 9: 80, 2016.

2. Liclican A, Serafini L, Xing W, Czerwieniec G, Steiner B, Wang $\mathrm{T}$, et al. Biochemical characterization of tirabrutinib and other irreversible inhibitors of Bruton's tyrosine kinase reveals differences in on - and off - target inhibition. Biochim Biophys Acta Gen Subj 1864: 129531, 2020.

3. Owen C, Berinstein NL, Christofides A, Sehn LH. Review of Bruton tyrosine kinase inhibitors for the treatment of relapsed or refractory mantle cell lymphoma. Curr Oncol 26: e233-e240, 2019.

4. Wu J, Zhang M, Liu D. Bruton tyrosine kinase inhibitor ONO/GS- 
4059: from bench to bedside. Oncotarget 8: 7201-7207, 2017.

5. Sekiguchi N, Rai S, Munakata W, Suzuki K, Handa H, Shibayama $\mathrm{H}$, et al. A multicenter, open-label, phase II study of tirabrutinib (ONO/GS-4059) in patients with Waldenström's macroglobulinemia. Cancer Sci 111: 3327-3337, 2020.

6. Dhillon S. Tirabrutinib: First Approval. Drugs 80: 835-840, 2020.

7. Owen RG, Treon SP, Al-Katib A, Fonseca R, Greipp PR, McMaster ML, et al. Clinicopathological definition of Waldenstrom's macroglobulinemia: consensus panel recommendations from the Second International Workshop on Waldenstrom's Macroglobulinemia. Semin Oncol 30: 110-115, 2003.

8. Morel P, Duhamel A, Gobbi P, Dimopoulos MA, Dhodapkar MV, McCoy $\mathrm{J}$, et al. International prognostic scoring system for Waldenstrom macroglobulinemia. Blood 113: 4163-4170, 2009.

9. Matsuo S, Imai E. Guidelines for the treatment of nephrotic syndrome, full version. Tokyo Igakusha 2012.

10. Owen RG, Kyle RA, Stone MJ, Rawstron AC, Leblond V, Merlini $\mathrm{G}$, et al. Response assessment in Waldenström macroglobulinaemia: update from the VIth International Workshop. Br J Haematol 160: 171-176, 2013.

11. Sekiguchi N. Waldenström macroglobulinemia: Japanese perception. Rinsho Ketsueki 60: 988-997, 2019.

12. . NCCN Clinical Practice Guidelines in Oncology (NCCN Guidelines ${ }^{\circledR}$ ) Waldenström Macroglobulinemia/Lymphoplasmacytic Lymphoma Version 1. 2022 - June 24, 2021 [Internet]. [cited 2021 Sep 14]. Available from: https://www.ncen.org/professionals/physician_ gls/pdf/waldenstroms.pdf.

13. Kastritis E, Leblond V, Dimopoulos MA, Kimby E, Staber P, Kersten MJ, et al. Waldenström's macroglobulinaemia: ESMO Clinical Practice Guidelines for diagnosis, treatment and followup. Ann Oncol 29: iv41-iv50, 2018.

14. The Japanese Society of Hematology. Practical Guidelines for Hematological Malignancies, 2018 revised version [Internet]. [cited 2021 Sep 14]. Available from: http://www.jshem.or.jp/gui-hemali/2 _3.html\#soron.

15. Yasuda H, Tsukune Y, Inano T, Mori Y, Ota Y, Komatsu N. Successful Long-Term Ibrutinib Treatment in a Hemodialysis Patient With Leukemic Nonnodal Mantle Cell Lymphoma. Clin Lymphoma Myeloma Leuk 21: 176-178, 2021.

16. Aw A, Hellman JM, Birner A, Davids MS. A complex case of ibrutinib treatment for a CLL patient on haemodialysis. Br J Haematol 181: 854-v7, 2018.

17. Vos JM, Gustine J, Rennke HG, Hunter Z, Manning RJ, Dubeau TE, et al. Renal disease related to Waldenström macroglobulinaemia: incidence, pathology and clinical outcomes. $\mathrm{Br} \mathrm{J}$ Haematol 175: 623-630, 2016.

18. Dimopoulos MA, Kastritis E. How I treat Waldenström macroglobulinemia. Blood 134: 2022-2035, 2019.

19. Audard V, Georges B, Vanhille P, Toly C, Deroure B, Fakhouri F, et al. Renal lesions associated with IgM-secreting monoclonal proliferations: revisiting the disease spectrum. Clin J Am Soc Nephrol 3: 1339-1349, 2008.

20. Chauvet S, Bridoux F, Ecotière L, Javaugue V, Sirac C, Arnulf B, et al. Kidney diseases associated with monoclonal immunoglobulin M-secreting B-cell lymphoproliferative disorders: a case series of 35 patients. Am J Kidney Dis 66: 756-767, 2015.

21. Gnemmi V, Leleu X, Provot F, Moulonguet F, Buob D. Cast nephropathy and light-chain deposition disease in Waldenström macroglobulinemia. Am J Kidney Dis 60: 487-491, 2012.

22. Narita $Y$, Nagane M, Mishima K, Terui Y, Arakawa Y, Yonezawa $\mathrm{H}$, et al. Phase I/II study of tirabrutinib, a second-generation Bruton's tyrosine kinase inhibitor, in relapsed/refractory primary central nervous system lymphoma. Neuro Oncol 23: 122-133, 2021.

23. Walter HS, Rule SA, Dyer MJ, Karlin L, Jones C, Cazin B, et al. A phase 1 clinical trial of the selective BTK inhibitor ONO/GS4059 in relapsed and refractory mature B-cell malignancies. Blood 127: 411-419, 2016.

24. Munakata W, Ando K, Hatake K, Fukuhara N, Kinoshita T, Fukuhara S, et al. Phase I study of tirabrutinib (ONO-4059/GS4059) in patients with relapsed or refractory B-cell malignancies in Japan. Cancer Sci 110: 1686-1694, 2019.

25. Drug interview form, Velexbru Tablets 80mg [Internet]. [cited 2021 Sep 14]. Available from: https://www.ono-oncology.jp/syste m/files/2020-11/VLX_IF_1.pdf.

The Internal Medicine is an Open Access journal distributed under the Creative Commons Attribution-NonCommercial-NoDerivatives 4.0 International License. To view the details of this license, please visit (https://creativecommons.org/licenses/ by-nc-nd/4.0/).

(C) The Japanese Society of Internal Medicine Intern Med Advance Publication 